\title{
OPTIMIZATION OF OBSERVATION PLAN BASED ON THE STOCHASTIC CHARACTERISTICS OF THE GEODETIC NETWORK
}

\author{
Wojciech Pachelski ${ }^{1}$, Paweł Postek ${ }^{2}$ \\ 1) Military University of Technology in Warsaw, \\ The Faculty of Civil Engineering and Geodesy, Poland \\ 2) University of Life Science in Lublin, Faculty of Production Engineering, Poland
}

\begin{abstract}
Optimal design of geodetic network is a basic subject of many engineering projects. An observation plan is a concluding part of the process. Any particular observation within the network has through adjustment a different contribution and impact on values and accuracy characteristics of unknowns. The problem of optimal design can be solved by means of computer simulation. This paper presents a new method of simulation based on sequential estimation of individual observations in a step-by-step manner, by means of the so-called filtering equations. The algorithm aims at satisfying different criteria of accuracy according to various interpretations of the covariance matrix. Apart of them, the optimization criterion is also amount of effort, defined as the minimum number of observations required.

A numerical example of a 2-D network is illustrated to view the effectiveness of presented method. The results show decrease of the number of observations by $66 \%$ with respect to the not optimized observation plan, which still satisfy the assumed accuracy.
\end{abstract}

Keywords: optimization, observation plan, horizontal network, cost, accuracy, covariance matrix, sequential adjustment

\section{Introduction}

Horizontal geodetic network is a collection of points connected by observations, that make up a specific geometric structure (Adamczewski, 2007). A network composition can be seen in terms of a class diagram of the Unified Modelling Language (UML), which is a modern tool for describing any information structure (Quatrani, 2003). This is showed in Figure 1, on which different entities of a network are linked together through specific relationships, such as association (simple line), navigation (line with an arrow), aggregation (line with a diamond) and specialization (line with a triangle); other entities as attributes, constraints, etc., are here omitted. Among the entities the 
most one is a reference frame (a datum), which decides on a definitive localization of the network points in space, and a variance - covariance matrix, or a cofactor matrix, which specifies relevant stochastic characteristics of the whole network, as well as of its individual segments.

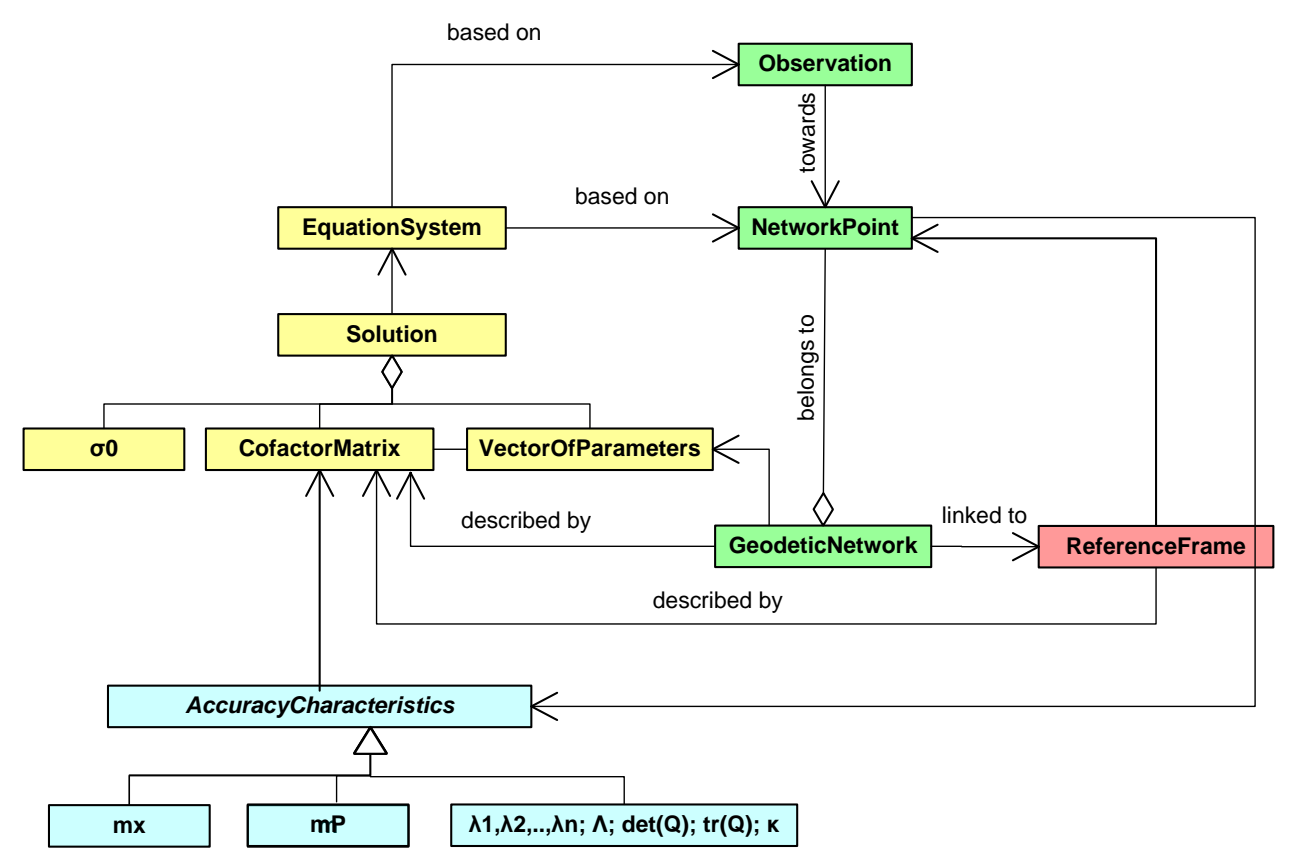

Fig. 1. Conceptual model of geodetic network.

A well designed network should meet required accuracy or/and reliability criteria, achieved at a low cost, by limiting the number of measuring stations and observations. Optimization of observation plan consists in searching for such a solution. Different optimization problems are defined into different orders. Grafarend (1974) identified four optimization orders:

1. Zero-Order Design (ZOD): design the reference system;

2. First-Order Design (FOD): design of the network configuration (also observation plan);

3. Second-Order Design (SOD): selection of appropriate weights for the observations;

4. Third-Order Design (TOD): extending or densifying an existing network by introducing additional points and/or additional observations.

Optimization of observation plan is the issue of FOD, and can be solved i.a. by the computer simulation. The main goal of this solution, is to solve the design problem by sequentially adding or subtracting selected observations, until a satisfactory network is found (Cross, 1985). Of the previously mentioned methods based on this solution, the most distinguishable are Nickerson (1979), Frank and Misslin (1980), Cross and Whiting (1981) Mepham (1983), Nowak (1985) or Chang (1996). Despite the fact that each of these methods is based on a different optimization strategy, adding or deleting an observation still depends on its weight. The main purpose of this paper is to present a different strategy of computer simulation, which is based on a sequential estimation. The strategy to be discussed uses the properly defined point accuracy and amount of measurement effort (equivalent to measurement costs) as optimization criteria. 


\section{Accuracy characteristics}

\subsection{The Gauss - Markov functional model}

First, we consider the so-called datum problem within the Gauss - Markov functional model without a priori information:

$$
\mathbf{I}+\mathbf{v}=\mathbf{A x}
$$

with the weight matrix $\mathbf{P}$. The model (1) is subject to the least squares principle:

where:

$$
\mathbf{v}^{\top} \mathbf{P} \mathbf{v}=\min
$$

$\underset{(\mathbf{n} \times \mathrm{m})}{\mathbf{A}}$ - design matrix,

$\underset{(\mathbf{n} \times n)}{\mathbf{P}}$ - weight matrix of observations,

$\underset{(\mathbf{m} \times m)}{\mathbf{X}}$ - vector of unknown parameters,

$\underset{(n \times 1)}{\text { I }}$ - a vector of observations

$\underset{(n \times 1)}{\mathbf{V}}$ - the vector of the least squares corrections,

Here, the vector of parameters $\mathbf{x}$, rather stands for small corrections to approximate values of station coordinates than the coordinates themselves. In a geodetic network the parameters $\mathbf{x}$ are usually point coordinates in one, two or three dimensions, while observations (measurements) I are usually height differences, angles (horizontal and/or vertical), and/or distances ${ }^{1}$. The point coordinates are to be inferred from a reference frame, or a datum, which defines, for the relevant network, proper coordinate system consisting of the origin, orientation and scale elements (Table 1).

Table 1. Number of elements required for complete definition of the datum (numbers in brackets correspond to the cases when scale is defined separately).

\begin{tabular}{|c|c|c|c|c|}
\hline \multirow{2}{*}{ Dimension } & \multicolumn{4}{|c|}{ Datum elements } \\
\cline { 2 - 5 } & Origin & Orientation & Scale & Total \\
\hline D-1 & 1 & - & 1 & $2(1)$ \\
\hline D-2 & 2 & 1 & 1 & $4(3)$ \\
\hline D-3 & 3 & 3 & 1 & $7(6)$ \\
\hline
\end{tabular}

As the considered observation types do not contain complete information on datum elements, the missing information in the model (1) cannot be solved uniquely for the parameters $\mathbf{x}$. This appears as the linear dependence of columns of the design matrix $\mathbf{A}$ and causes the singularity of the normal equations matrix $\mathbf{A}^{\top} \mathbf{P} \mathbf{A}$, with $\operatorname{det}\left(\mathbf{A}^{\top} \mathbf{P A}\right)=0$. The normal equations matrix is not considered here as of the full rank, but as a rank deficient with the rank defect $d>0$, where:

${ }^{1}$ In this analysis we disregard other types of observations, such as GNSS ones, which require a separate approach. 


$$
d=r\left(A^{\top} P A\right)-u
$$

and $u$ is the number of undefined elements of the reference frame (the datum), see Table 1. This is the datum problem which consists in providing some additional information to resolve the rank defect to arrive at $d=0$. This can be done either through supplementary observations to link the existing network points to other points of known positions within the given datum, or through adopting some a priori constraints on the unknown parameters $\mathbf{x}$.

Following Caspary (1987) we may request that any datum definition shall impose no strain on the network, so that it shall not affect the network geometry. The desired equation is equivalent to the requirement that relative positions of the points should result solely from the basic observations. In the following we assume the rank defect due to the datum problem has been removed, so that we have a regular normal equations matrix which leads to a unique cofactor matrix:

$$
Q_{x}=\left(A^{\top} P A\right)^{-1}
$$

\subsection{Specific accuracy characteristics}

All accuracy characteristics of a network are embedded in its variance - covariance matrix:

$$
\hat{\mathbf{Q}}_{\mathrm{x}}=\sigma_{0}^{2} \mathbf{Q}_{\mathrm{x}}
$$

in which vector of unknowns $\mathbf{x}$ and its cofactor matrix $\mathbf{Q}_{\mathbf{x}}$ are given through the wellknown solution of normal equations, resulting from (2):

with

$$
X=\left(A^{\top} P A\right)^{-1} A^{\top} P I
$$

$$
Q_{\mathrm{x}}=\left(\mathrm{A}^{\top} \mathrm{PA}\right)^{-1}
$$

provided that there is no datum defect, so that $d=0$. We have also

$$
\sigma_{0}^{2}=\frac{\mathbf{v}^{\top} \mathbf{P v}}{\mathbf{n}-\mathbf{u}}
$$

Any chosen network accuracy characteristics may refer either to the matrix $\hat{\mathbf{Q}}_{\mathrm{x}}$ as a whole, or to any its diagonal submatrix $\hat{\mathbf{Q}}_{\mathbf{x}}$, not necessarily consistent, being also a variance - covariance matrix representing a specific "sub-net" of the given network with columns and rows relevant to 1-D, 2-D or 3-D coordinates of network points. This is roughly illustrated in Figure 2. Further we denote the variance - covariance matrix or any of its sub-matrices by $\hat{\mathbf{Q}}$.

Any matrix $\hat{\mathbf{Q}}$ defines an $\mathrm{r}$-dimensional hyper-ellipsoid (an ellipse in 2-D, an ellipsoid in 3-D) in the space of the parameters $x$ through the equation:

with $r(\mathbf{Q})=r$ as the rank of $\mathbf{Q}$.

$$
\mathbf{X}^{\top} \hat{\mathbf{Q}}^{-1} \mathbf{X}=\mathbf{1}
$$




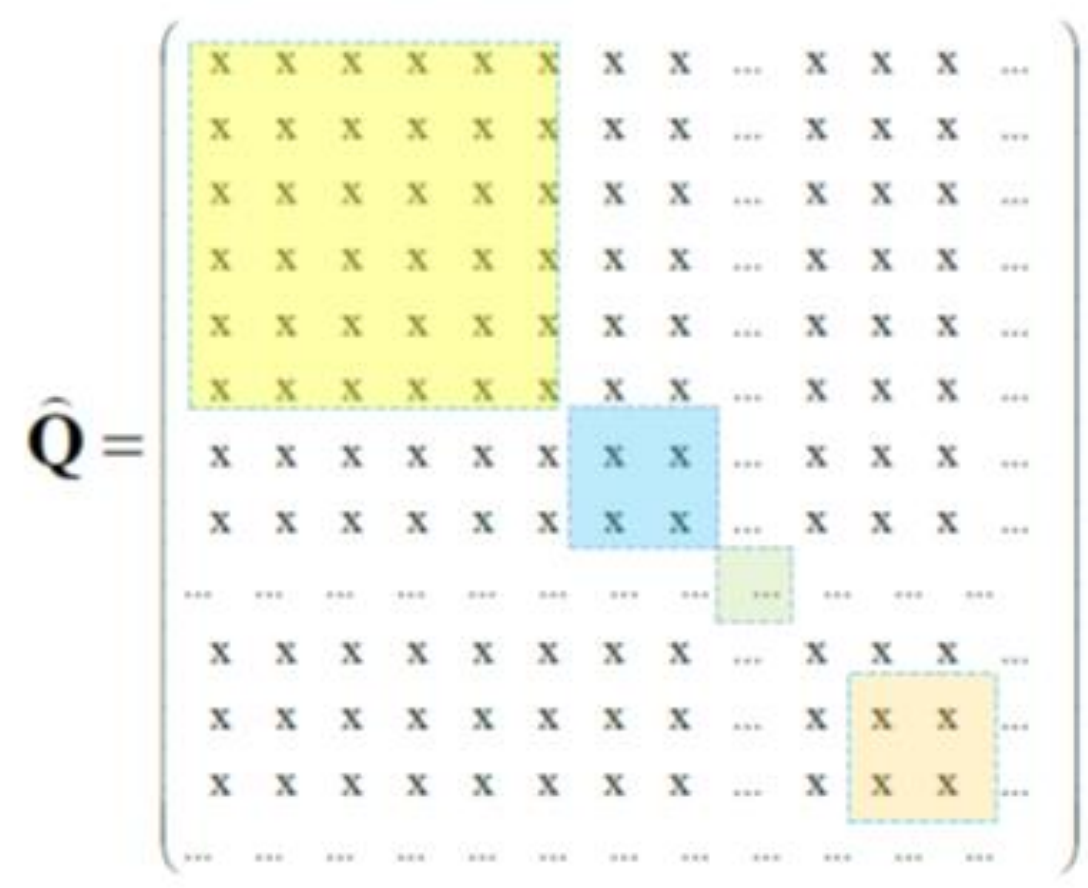

Fig. 2. The variance-covariance matrix and some of its diagonal submatrices.

Then among the accuracy characteristics of the network are:

- lengths of the hyper-ellipsoid semi-axes:

$$
a=\sqrt{\lambda_{1}}, b=\sqrt{\lambda_{2}}, c=\sqrt{\lambda_{3}}, \ldots, \ldots=\sqrt{\lambda_{r}},
$$

- orientation of the semi-axes given by the matrix:

$$
W=\left(\begin{array}{lllll}
w_{1} & w_{2} & w_{3} & \ldots & w_{r}
\end{array}\right)
$$

where $\lambda_{i}$ and $\mathbf{w}_{i}, \quad(\mathbf{i}=1,2, \ldots, r)$, are eigenvalues and eigenvectors of $\hat{\mathbf{Q}}$ satisfying the equations:

$$
\operatorname{det}(\hat{\mathbf{Q}}-\lambda \mathrm{I})=\mathbf{0} \quad\left(\hat{\mathbf{Q}}-\lambda_{\mathrm{i}} \mathrm{l}\right) \mathbf{w}_{\mathrm{i}}=\mathbf{0}
$$

it is worth to note that $\lambda_{i}$ and $w_{i}$ are invariant with linear transformations of $\mathbf{x}$.

- other accuracy characteristics:

$\widehat{\mathbf{q}}_{\mathbf{x}_{\mathrm{i}}}$ - variance of a single parameter,

$\operatorname{tr}(\hat{\mathbf{Q}})=\sum \lambda_{i}-$ generalized Helmert's point position error, $\operatorname{det}(\hat{\mathbf{Q}})=\prod \lambda_{\mathrm{i}}-$ generalized hyper-ellipsoid volume (accurate to a constant factor),

$\kappa=\frac{\lambda_{\min }}{\lambda_{\max }}-$ conditional number. 


\section{Optimization algorithm}

In the theory of sequential estimation based on Kalman filter there are equations that update covariance matrix by adding new observations. The equations, commonly known as filtering equations, were derived in the works of Lee (1964) and Pachelski (1972). The equations have form:

- for equally weighted observations:

$$
C_{k+\alpha}=C_{k}-C_{k} \alpha\left(\alpha^{\top} C_{k} \alpha+1\right)^{-1} \alpha^{\top} C_{k}
$$

- for not equally weighted observations:

where

$$
C_{k+\alpha}=C_{k}-C_{k} \alpha\left(\alpha^{\top} C_{k} \alpha+\sigma^{2}\right)^{-1} \alpha^{\top} C_{k}
$$

$\mathbf{C}_{k+\alpha}$-the covariance matrix updated by a single observation

$\mathbf{C}_{\mathrm{k}}$ - the output covariance matrix

$\alpha$ - coefficients of the new observation equation

$\boldsymbol{\sigma}$ - observation mean error.

The advantage of this method is the acceleration of the calculation process. In next addition to the filtering algorithm we also need a strategy for adding subsequent observations, which will allow to exam the impact of each individual observation on the covariance matrix. This strategy, in the form of a UML diagram is shown in the Figure 3. In the first stage of optimization process, we enter approximate location of points (measuring stations and reference system) and define the value of accuracy criterion. The next step is generation of the output covariance matrix $\mathbf{C}_{\mathbf{k}}$, which is the zero-diagonal matrix with very large variance (theoretically should be infinity), crippled the highest possible defect, provided for horizontal network. The strategy of adding observations is based on a specially programed loop, which allows for using a filter equation to create a potential observation plans in different configurations. In each configuration, the impact of added observations on covariance matrix is analyzed. The configuration where the accuracy criterion is fulfilled with the minimum number of observations would be the optimal plan.

\section{Numerical test}

Below is an example demonstrating the optimization of an observation plan according to the discussed algorithm. The algorithm reduces the number of angular and distance observations in a horizontal control network of a railway viaduct. The required accuracy for point positions is $m_{p}= \pm 1 \mathrm{~cm}$, while the rms errors of distance measurements is $m_{d}=1 \mathrm{~cm}+1 \mathrm{ppm} \times D$ and that of angular measurements is $m_{\alpha}=$ $10^{c c}$. The assumption was also centering rms errors of a measuring station equal $\mathrm{m}_{\mathrm{s}}$ $= \pm 3 \mathrm{~mm}$ and those of a target equal $\mathrm{m}_{\mathrm{c}}= \pm 5 \mathrm{~mm}$. The results of the optimization process clearly indicate a significant reduction of the number of observations without degradation of the required point position accuracy.

A sketch of the network before optimization is shown in Fig. 4 and after the optimization in Fig. 5, while the corresponding covariance matrices are given in Tables 2 and 3 . Table 4 gives numbers of observations of both types before and after the optimization. 


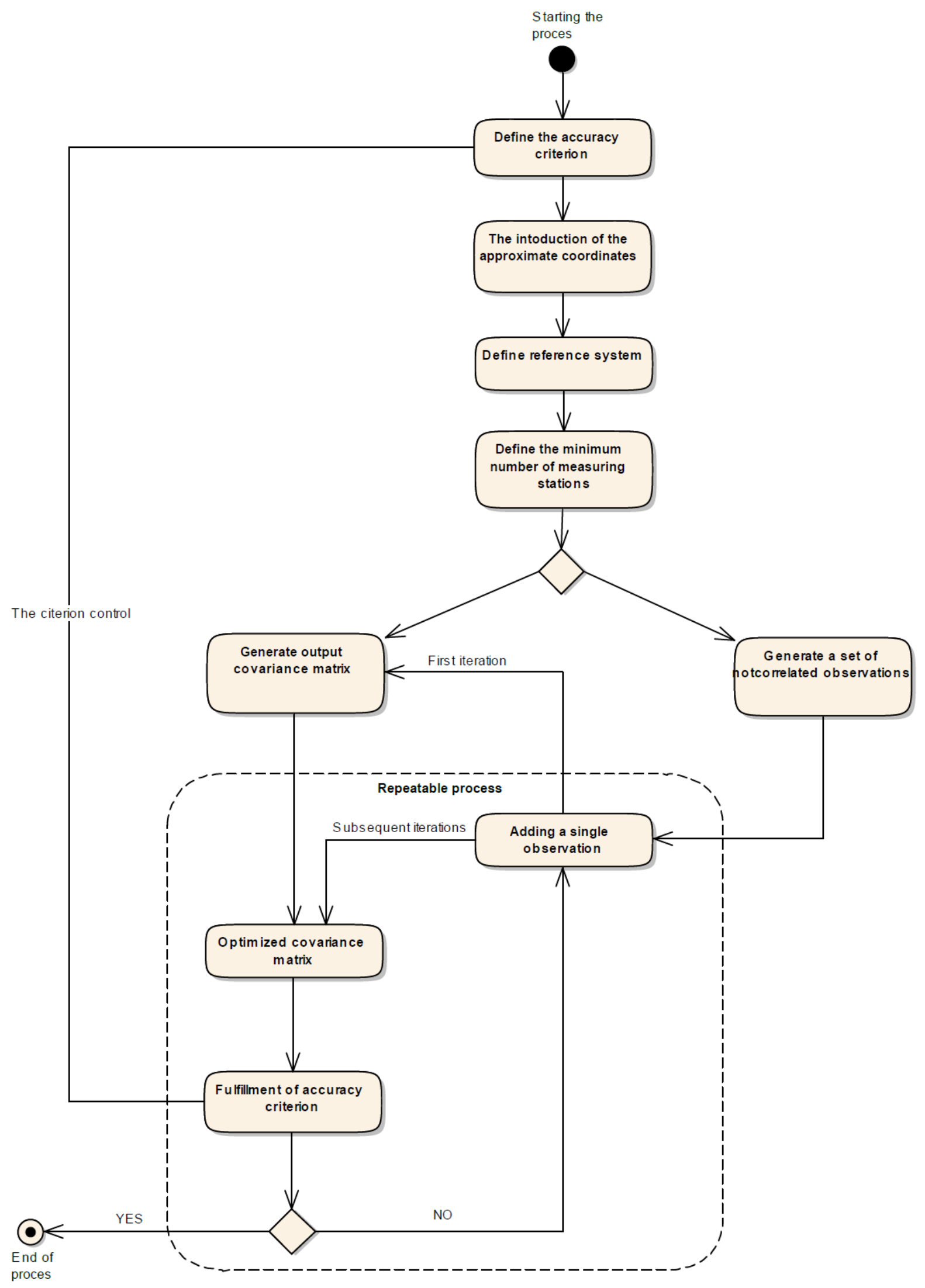

Fig. 3. Conceptual model optimization strategy. 


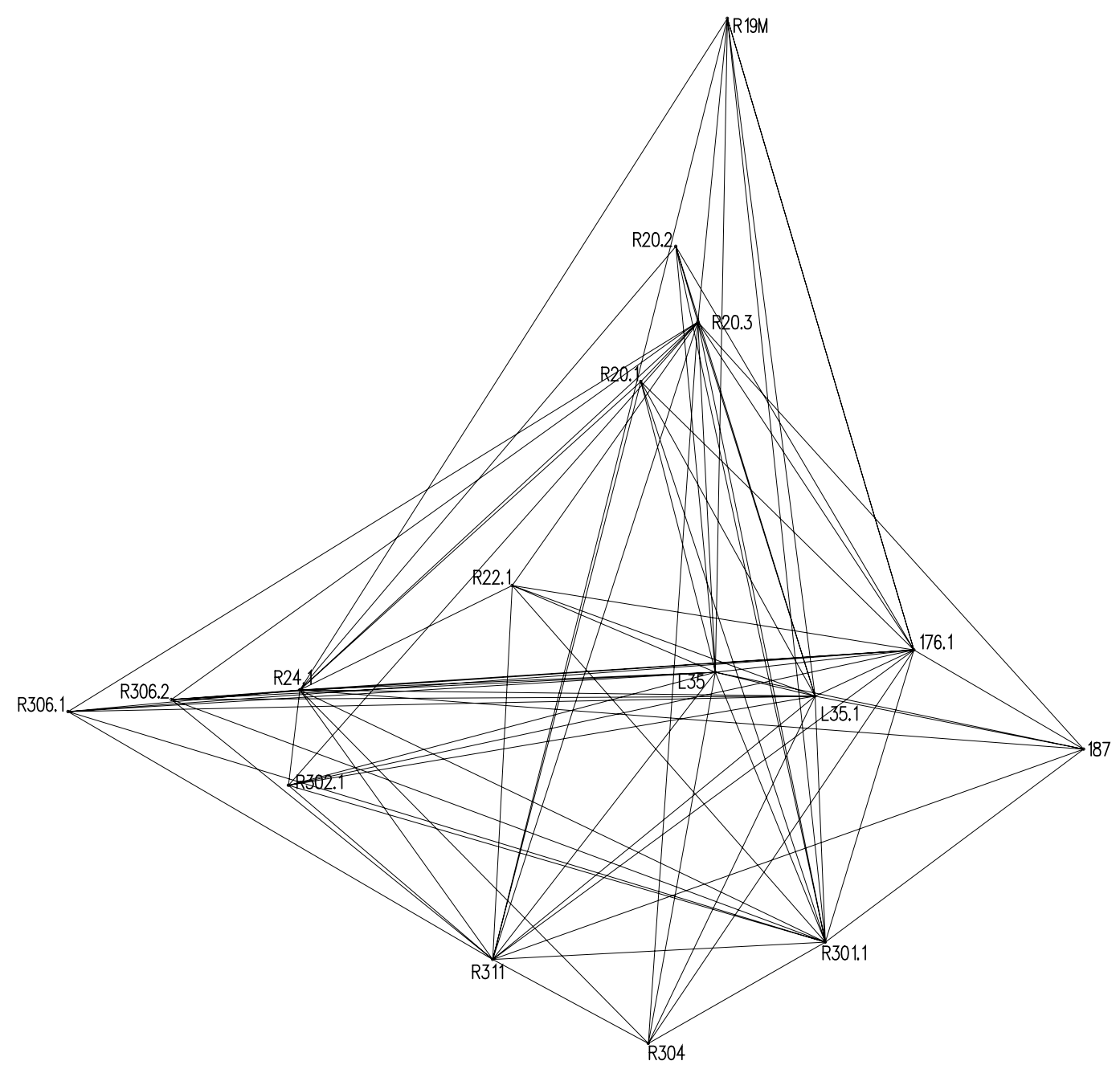

Fig. 4. A layout of the network before optimization

Table 2. Covariance matrix of analyzed network before optimization

\begin{tabular}{|r|r|r|r|r|r|r|r|r|r|r|r|r|r|}
\hline $\mathbf{0 , 0 4 6}$ & $\mathbf{- 0 , 0 0 2}$ & 0,002 & $-0,002$ & $-0,001$ & $-0,001$ & 0,000 & 0,000 & 0,001 & $-0,001$ & 0,000 & $-0,001$ & 0,003 & 0,000 \\
\hline $\mathbf{- 0 , 0 0 2}$ & $\mathbf{0 , 0 5 7}$ & 0,001 & 0,002 & 0,001 & 0,003 & 0,003 & 0,000 & 0,001 & 0,002 & 0,001 & 0,003 & 0,000 & 0,000 \\
\hline 0,002 & 0,001 & $\mathbf{0 , 0 4 3}$ & $\mathbf{- 0 , 0 0 5}$ & 0,023 & $-0,003$ & 0,004 & $-0,001$ & 0,006 & 0,001 & 0,028 & 0,004 & 0,005 & $-0,003$ \\
\hline$-0,002$ & 0,002 & $\mathbf{- 0 , 0 0 5}$ & $\mathbf{0 , 0 5 8}$ & $-0,005$ & 0,010 & $-0,001$ & 0,008 & 0,005 & 0,017 & $-0,001$ & 0,016 & $-0,002$ & 0,007 \\
\hline$-0,001$ & 0,001 & 0,023 & $-0,005$ & $\mathbf{0 , 0 4 3}$ & $\mathbf{0 , 0 0 2}$ & 0,004 & $-0,001$ & 0,005 & $-0,004$ & 0,025 & $-0,006$ & 0,003 & $-0,002$ \\
\hline$-0,001$ & 0,003 & $-0,003$ & 0,010 & $\mathbf{0 , 0 0 2}$ & $\mathbf{0 , 0 7 1}$ & 0,002 & 0,004 & 0,005 & 0,016 & $-0,007$ & 0,029 & 0,002 & 0,003 \\
\hline 0,000 & 0,003 & 0,004 & $-0,001$ & 0,004 & 0,002 & $\mathbf{0 , 0 7 2}$ & $\mathbf{- 0 , 0 0 2}$ & 0,002 & 0,000 & 0,004 & 0,000 & 0,001 & 0,002 \\
\hline 0,000 & 0,000 & $-0,001$ & 0,008 & $-0,001$ & 0,004 & $\mathbf{- 0 , 0 0 2}$ & $\mathbf{0 , 0 2 9}$ & 0,001 & 0,002 & $-0,001$ & 0,004 & 0,001 & 0,000 \\
\hline 0,001 & 0,001 & 0,006 & 0,005 & 0,005 & 0,005 & 0,002 & 0,001 & $\mathbf{0 , 0 6 4}$ & $\mathbf{0 , 0 1 1}$ & 0,008 & 0,010 & 0,004 & $-0,002$ \\
\hline$-0,001$ & 0,002 & 0,001 & 0,017 & $-0,004$ & 0,016 & 0,000 & 0,002 & $\mathbf{0 , 0 1 1}$ & $\mathbf{0 , 0 5 8}$ & 0,002 & 0,029 & 0,001 & 0,005 \\
\hline 0,000 & 0,001 & 0,028 & $-0,001$ & 0,025 & $-0,007$ & 0,004 & $-0,001$ & 0,008 & 0,002 & $\mathbf{0 , 0 4 8}$ & $\mathbf{0 , 0 0 4}$ & 0,005 & $-0,002$ \\
\hline$-0,001$ & 0,003 & 0,004 & 0,016 & $-0,006$ & 0,029 & 0,000 & 0,004 & 0,010 & 0,029 & $\mathbf{0 , 0 0 4}$ & $\mathbf{0 , 0 6 7}$ & 0,001 & 0,005 \\
\hline 0,003 & 0,000 & 0,005 & $-0,002$ & 0,003 & 0,002 & 0,001 & 0,001 & 0,004 & 0,001 & 0,005 & 0,001 & $\mathbf{0 , 0 5 0}$ & $\mathbf{0 , 0 0 0}$ \\
\hline 0,000 & 0,000 & $-0,003$ & 0,007 & $-0,002$ & 0,003 & 0,002 & 0,000 & $-0,002$ & 0,005 & $-0,002$ & 0,005 & $\mathbf{0 , 0 0 0}$ & $\mathbf{0 , 0 6 8}$ \\
\hline
\end{tabular}




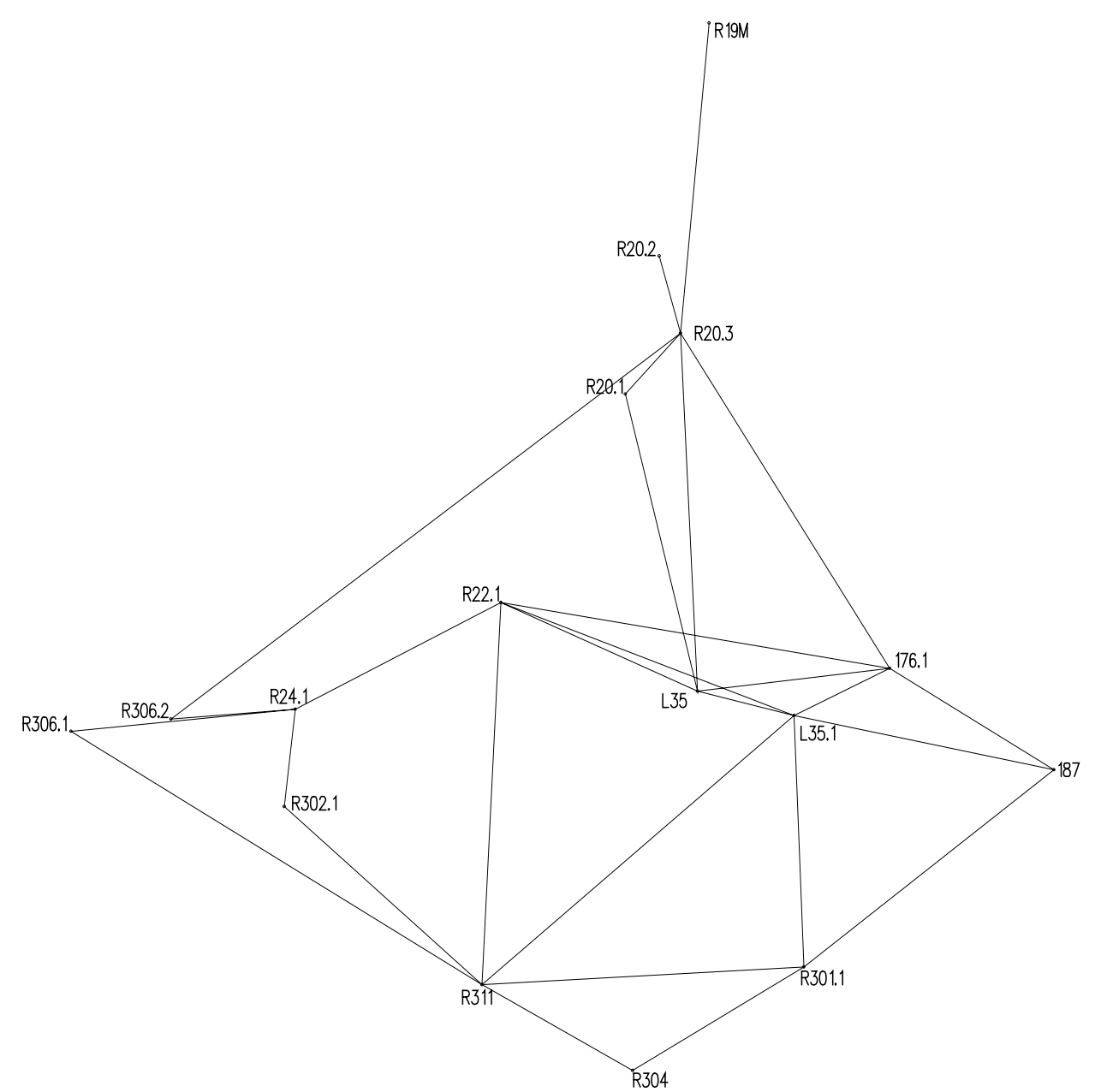

Fig. 5. A layout of the network after optimization

Table 3. Covariance matrix of analyzed network after optimization

\begin{tabular}{|r|r|r|r|r|r|r|r|r|r|r|r|r|r|r|}
\hline $\mathbf{0 , 6 2 0}$ & $\mathbf{0 , 0 0 1}$ & 0,001 & $-0,012$ & $-0,006$ & $-0,005$ & $-0,003$ & 0,000 & $-0,001$ & $-0,001$ & $-0,003$ & $-0,002$ & 0,004 & 0,000 \\
\hline $\mathbf{0 , 0 0 1}$ & $\mathbf{0 , 7 5 0}$ & 0,003 & 0,001 & 0,005 & 0,002 & 0,002 & 0,000 & 0,001 & $-0,002$ & 0,003 & $-0,001$ & 0,003 & $-0,014$ \\
\hline 0,001 & 0,003 & $\mathbf{0 , 9 3 0}$ & $\mathbf{- 0 , 0 0 7}$ & 0,061 & 0,021 & 0,009 & 0,000 & 0,007 & $-0,005$ & 0,066 & 0,016 & 0,002 & 0,000 \\
\hline$-0,012$ & 0,001 & $\mathbf{- 0 , 0 0 7}$ & $\mathbf{0 , 2 6 8}$ & 0,024 & 0,062 & 0,002 & 0,014 & 0,021 & 0,035 & 0,021 & 0,055 & 0,004 & 0,001 \\
\hline$-0,006$ & 0,005 & 0,061 & 0,024 & $\mathbf{0 , 1 2 3}$ & $\mathbf{0 , 0 6 6}$ & 0,009 & 0,001 & 0,008 & $-0,021$ & 0,067 & $-0,005$ & $-0,003$ & 0,001 \\
\hline$-0,005$ & 0,002 & 0,021 & 0,062 & $\mathbf{0 , 0 6 6}$ & $\mathbf{0 , 2 0 6}$ & 0,000 & 0,004 & 0,028 & 0,043 & 0,016 & 0,083 & 0,005 & 0,003 \\
\hline$-0,003$ & 0,002 & 0,009 & 0,002 & 0,009 & 0,000 & $\mathbf{0 , 1 2 5}$ & $\mathbf{0 , 0 0 7}$ & 0,000 & $-0,002$ & 0,007 & 0,000 & $-0,005$ & 0,011 \\
\hline 0,000 & 0,000 & 0,000 & 0,014 & 0,001 & 0,004 & $\mathbf{0 , 0 0 7}$ & $\mathbf{0 , 5 0}$ & 0,001 & 0,002 & 0,001 & 0,003 & 0,002 & $-0,003$ \\
\hline$-0,001$ & 0,001 & 0,007 & 0,021 & 0,008 & 0,028 & 0,000 & 0,001 & $\mathbf{0 , 1 0 8}$ & $\mathbf{0 , 0 3 8}$ & 0,013 & 0,037 & 0,007 & $-0,010$ \\
\hline$-0,001$ & $-0,002$ & $-0,005$ & 0,035 & $-0,021$ & 0,043 & $-0,002$ & 0,002 & $\mathbf{0 , 0 3 8}$ & $\mathbf{0 , 1 2 6}$ & $-0,002$ & 0,082 & 0,012 & 0,006 \\
\hline$-0,003$ & 0,003 & 0,066 & 0,021 & 0,067 & 0,016 & 0,007 & 0,001 & 0,013 & $-0,002$ & $\mathbf{0 , 8 8 0}$ & $\mathbf{0 , 0 1 5}$ & 0,005 & $-0,003$ \\
\hline$-0,002$ & $-0,001$ & 0,016 & 0,055 & $-0,005$ & 0,083 & 0,000 & 0,003 & 0,037 & 0,082 & $\mathbf{0 , 0 1 5}$ & $\mathbf{0 , 1 4 4}$ & 0,008 & 0,009 \\
\hline 0,004 & 0,003 & 0,002 & 0,004 & $-0,003$ & 0,005 & $-0,005$ & 0,002 & 0,007 & 0,012 & 0,005 & 0,008 & $\mathbf{0 , 1 1 7}$ & $\mathbf{- 0 , 0 5 3}$ \\
\hline 0,000 & $-0,014$ & 0,000 & 0,001 & 0,001 & 0,003 & 0,011 & $-0,003$ & $-0,010$ & 0,006 & $-0,003$ & 0,009 & $\mathbf{- 0 , 0 5 3}$ & $\mathbf{0 , 1 8 5}$ \\
\hline
\end{tabular}

Table 4. A quantitative observation list

\begin{tabular}{|c|c|c|c|}
\hline & Before optimization & After optimization & Difference [\%] \\
\hline Distance & 83 & 28 & $66 \%$ \\
\hline Angles & 104 & 47 & $55 \%$ \\
\hline
\end{tabular}




\section{Conclusions}

- The method allows to eliminate those observations, which due to the geometry of the network and the optimization criteria have minor contribution to the final point position accuracy;

- As an optimization criteria any accuracy characteristic resulting from the variance - covariance matrix can be taken into account;

- According to the algorithm, any observation can be analyzed with respect to its impact on the variance - covariance matrix;

- The method can be used in conjunction with any other optimization criteria such as for example the coefficient of reliability.

\section{References}

Adamczewski, Z. (2007). Rachunek Wyrównawczy w 15 wykładach, Oficyna Wydawnicza Politechniki Warszawskiej, Warszawa.

Baran, W. (1982). Some new procedures of the sequential adjustment. Int. Symp. of Geodetic Networks and Computations, Deutsche Geodatische Kommission, Munich, VIII:69-79.

Bernè, J. L. \& Baselga, S. (2004). First-order design of geodetic networks using the simulated annealing method, Journal of Geodesy 78:47-54.

Caspary, W. F. (1987). Concepts of network and deformation analysis, Monograph 11, The University of New South Wales, Australia.

Chang, Y. M., Chen, C. H. \& Chen, C. S. (1996). Optimal observation design of surveying network using artificial neural network. Geomat Res Aust 64:1-16.

Cross, P. A. (1985). Numerical Methods in Network Design, Springer - Verlag Berlin Heidelberg.

Grafarend, E. (1974). Optimization of geodetic network, Boll Geod. Sci. Aff. 33: 351-406.

Hausbrandt, S. (1971). Rachunek Wyrównawczy i Obliczenia Geodezyjne, Tom II, Państwowe Przedsiębiorstwo Wydawnictw Kartograficznych, Warszawa.

Lee, R. C. K. (1964). Optimal Estimation, Identification and Control, Research Monograph, M.I.T. Press, Cambridge.

Nickerson, B. G. (1979). Horizontal network design using interactive computer graphics, MScEng Thesis, University of New Brunswick, Canada.

Nowak, E. (1985). Interactive network design analysis based on successive modifications of covariance matrix. $7^{\text {th }}$ International Symposium on Geodetic Computations IUGG, Zesz. Nauk. AGH Geodezja 90/1985, Kraków.

Pachelski, W. (1972). Teoria równań filtrujących i ich zastosowanie do opracowania obserwacji według metody najmniejszych kwadratów, Państwowe Wydawnictwo Naukowe, Warszawa.

Pachelski, W. (1981). Macierze kowariancji geodezyjnych obserwacji satelitarnych, Zakład Geodezji Planetarnej Centrum Badań Kosmicznych PAN, Warszawa.

Prószyński, W. (1980). Podstawy analiz dokładnościowych w geodezyjnych pomiarach realizacyjnych, Geodezja Inżynieryjna Tom II, Wydawnictwo PWK.

Prószyński, W. \& Kwaśniak, M. (2006). Podstawy geodezyjnego wyznaczania przemieszczeń. Pojęcia i elementy metodyki, Oficyna Wydawnicza Politechniki Warszawskiej, Warszawa.

Quatrani, T. (2003). Introduction to the Unified Modeling Language, IBM Rational Software. 
Wiśniewski, Z. (2009). Rachunek Wyrównawczy w Geodezji (z przykładami), Kolegium Wydawnicze UWM, Olsztyn.

\section{Authors:}

Wojciech Pachelski ${ }^{1)}$, wojciech.pachelski@wat.edu.pl

Paweł Postek ${ }^{2)}$, pawel.postek@up.lublin.pl

1) Faculty of Civil Engineering and Geodesy,

Military University of Technology

Kaliskiego St. 2, 00-908, Warsaw, Poland

2) University of Life Science in Lublin,

Department of Environmental Engineering and Geodesy,

kr. St. Leszczyńskiego St. 7, 20-069 Lublin, Poland 